\title{
Oxidation of Ethylene on Oxygen Reconstructed
}

\section{Silver Surfaces}

Travis E Jones ${ }^{1, *}$, Regina Wyrwich ${ }^{2}$, Sebastian Böcklein ${ }^{2, \dagger}$, Tulio C. R. Rocha ${ }^{3}$,Emilia A.

Carbonio $^{1,4}$, Axel Knop-Gericke ${ }^{1}$, Robert Schlögl ${ }^{1}$, Sebastian Günther ${ }^{5}$, Joost Wintterlin ${ }^{2}$, Simone

Piccinin $^{6}$

1 Abteilung Anorganische Chemie Department, Fritz-Haber-Institut der Max-PlanckGesellschaft, Faradayweg 4-6, 14195 Berlin (Germany). 2 Department Chemie, LudwigMaximilians-Universität München, Butenandtstr. 5-13, 81377 Munich (Germany). 3 Brazilian Synchrotron Light Laboratory, Caixa Postal 6192, CEP 13083-970, Campinas (Brazil). 4 Helmholtz-Zentrum Berlin für Materialien und Energie GmbH, BESSY II, Albert-Einstein-Str. 15, 12489 Berlin (Germany). 5 Chemie Department, Technische Universität München, Lichtenbergstr. 4, 85748 Garching (Germany). 6 CNR-IOM DEMOCRITOS, Consiglio Nazionale delle Ricerche- Instituto Officina dei Materiali c/o SISSA, Via Bonomea 267, 34136 Trieste (Italy).

$†$ Current Address: Clariant Produkte (Deutschland) GmbH, Waldheimer Str. 13, 83052

Bruckmühl (Germany) 


\begin{abstract}
We report on theoretical and experimental studies of the reactivity of ethylene with oxygen in two well-known oxygen induced surface reconstructions on silver, the $\mathrm{p}(2 \mathrm{x} 1)$ reconstruction on the $\operatorname{Ag}(110)$ and the $\mathrm{p}(4 \mathrm{x} 4)$ reconstruction on the $\mathrm{Ag}(111)$ surfaces. Density functional theory calculations demonstrate that ethylene can react with oxygen on both surfaces to form an oxametallacycle that can decompose into either ethylene oxide or a $\mathrm{CO}_{2}$ precursor, acetaldehyde. The activation energy associated with acetaldehyde formation is predicted to be $0.4 \mathrm{eV}$ lower than that associated with epoxide formation on both surfaces, though we find lower barriers for all elementary steps on the $\mathrm{p}(4 \mathrm{x} 4)$ reconstruction due to its unique structural dynamics. Our calculations predict these dynamics make the $\mathrm{p}(4 \mathrm{x} 4)$ reconstruction active in acetaldehyde formation at room temperature. Experiments performed by exposing the $\mathrm{p}(4 \mathrm{x} 4)$ reconstruction to ethylene at room temperature support this finding with $\mathrm{CO}_{2}$ the only carbonaceous product formed during temperature programed desorption. Our results unambiguously demonstrate that, alone, these oxygen reconstructions are not selective in ethylene epoxidation on silver.
\end{abstract}

\title{
Introduction
}

The unique ability of silver to catalyze the partial oxidation of ethylene to ethylene oxide in $\mathrm{O}_{2}$ has long been of interest to the chemistry community and is the subject of numerous reviews [14]. In this apparently simple reaction a single oxygen atom is added to ethylene to yield ethylene epoxide. The challenge and interest arises from the fact that ethylene oxide is not the thermodynamically favored product under an oxidizing atmosphere, $\mathrm{CO}_{2}$ is. Yet, unpromoted silver has the ability to produce the epoxide with nearly $50 \%$ selectivity, a value that can be 
increased to over $90 \%$ with the addition of promoters and inhibitors [1-5]. Identifying the origin of this behavior under realistic conditions is one of the most fundamental challenges in heterogeneous catalysis.

There is widespread agreement that ethylene epoxidation occurs through a LangmuirHinshelwood mechanism [6], with the notable exception of ethylene epoxidation on $\operatorname{Ag}_{2} \mathrm{O}$, where computational studies suggest EO is produced through an Eley-Rideal type mechanism if no $\mathrm{Ag}^{\delta+}$ surface sites are available for ethylene adsorption [7, 8]. However, there is no consensus on the nature of the species active in epoxidation and combustion [6]. Thermodynamic considerations are often used to rule out the involvement of $\mathrm{Ag}_{2} \mathrm{O}$, as the bulk oxide is not stable under epoxidation conditions [11-6, 9]. Instead, at the oxygen chemical potentials required for epoxidation surface reconstructions with $\mathrm{Ag}^{\delta+}$ sites available for ethylene adsorption are formed $[6,10,11]$. Such structures have been observed directly by scanning tunneling microscopy (STM) $[10,11]$ and the presence of chemically similar oxygen species under near ambient pressure conditions can also be inferred by in situ X-ray photoelectron and near edge X-ray absorption spectroscopies (XPS and NEXAFS) [12-15]. (Note that in the earlier publications the $\mathrm{p}(4 \mathrm{x} 4)$ phase on $\mathrm{Ag}(111)$, which has played a central role in the discussion, was considered a $2 \mathrm{D}$ oxide-like structure but in 2006/2007 was shown to be a reconstruction [16-18].) Such results have similarly been predicted by ab initio calculations suggesting that silver surfaces are covered with oxygen-induced surface reconstructions at the oxygen chemical potentials typical for epoxidation under industrial conditions, while a low coverage of oxygen adatoms on an unreconstructed Ag surface is only stable at lower oxygen chemical potentials $[9,15]$. However, due to the long-standing difficulty associated with resolving the structure of some of these 
surface reconstructions [16-19], we know of no complete theoretical study of their behavior in epoxidation. Thus, their role remains unclear.

One common hypothesis is that the surface reconstructions serve to produce $\mathrm{Ag}^{\delta+}$ sites for ethene adsorption and that the partially ionic oxygen involved in the reconstructions can only participate in total oxidation [20]. Titration of the oxygen induced $\mathrm{p}(2 \mathrm{x} 1)$ reconstruction on an $\operatorname{Ag}(110)$ single crystal with ethylene appears to confirm this view, as only $\mathrm{CO}_{2}$ is produced in such experiments [21]. However, a second hypothesis is that oxygen in these surface reconstructions can be incorporated in ethylene oxide [22]. In support of this view, temperature programmed reduction of supported silver catalysts yields epoxide with near $50 \%$ selectivity [23], where the active species was argued to be consistent with the high coverage of oxygen on the $\operatorname{Ag}(111)$ surface typical in, for example, the $\mathrm{p}(4 \mathrm{x} 4)$ reconstruction [16-19].

Contrast this state of knowledge to that of adsorbed atomic oxygen on unreconstructed $\mathrm{Ag}$ surfaces. Experimentally, STM measurements performed at $4 \mathrm{~K}$ reveal that such a state might be present when the oxygen coverage is below 0.05 ML [24], above which coverage reconstructions nucleate [24]. However, low-energy electron microscopy (LEEM) experiments performed at $\sim 500 \mathrm{~K}$ are unable to confirm the presence of this low-coverage phase of partially-ionic unreconstructed atomic oxygen $[25,26]$ and establish an upper limit of $0.03 \mathrm{ML}$ for such a phase [26]. Despite this discrepancy, numerous density functional theory (DFT) calculations have been performed on the mechanism of ethylene epoxidation on silver with adsorbed atomic oxygen on unreconstructed Ag surfaces. These have revealed, in agreement with kinetic isotope studies [27], that epoxidation and combustion can proceed through a common intermediate [28-33]. Within this mechanism the common intermediate, an adsorbed oxametallacycle (OMC), can isomerize to $\mathrm{EO}$ or acetaldehyde $(\mathrm{AcH})$, which rapidly burns $[34,35]$. Because the two 
isomerization pathways are associated with competing elementary steps, the difference between the activation energies of them is often viewed as providing a computationally accessible upper limit of EO selectivity. However, because the two activation energies are often quite similar the predicted selectivity is near 50\% for all surfaces, oxygen coverages, and binding sites [32], while experimentally selectivity is sensitive to materials, conditions, and sample history $[1-6,12,14]$. Furthermore, there is scarce evidence that a measurable amount of the more ionic type of oxygen modeled by DFT is present under epoxidation conditions $[15,36]$ because it forms surface reconstructions at oxygen chemical potentials relevant for ethylene epoxidation $[10,19,21]$.

Herein we investigate the behavior of two well-known and well-characterized oxygen reconstructed silver surfaces, the $\mathrm{p}(4 \times 4)$ structure on the $\operatorname{Ag}(111)$ surface and the $\mathrm{p}(2 \mathrm{x} 1)$ structure on the $\operatorname{Ag}(110)$ surface, with ethylene in an effort to identify the role of these types of surfaces in ethylene epoxidation. Through a combination of calculated minimum energy paths and surface science experiments we conclude that the $\mathrm{Ag}^{\delta+}$ sites in the reconstructions can adsorb ethylene, but that the oxygen in these surface reconstructions can only participate in total combustion. This observation supports the idea that a second species [5, 12, 14, 20, 25], often referred to as electrophilic oxygen, is required for ethylene epoxidation.

\section{Theoretical and Experimental Methods}

DFT calculations were performed with the Quantum ESPRESSO package [37] using the Perdew, Burke, and Ernzerhof (PBE) exchange and correlation [38]. We used ultrasoft pseudopotentials taken from the PS library [39] with a kinetic energy (charge density) cutoff of 30 Ry (300 Ry) and Marzari-Vanderbilt cold smearing [40] with a smearing parameter of 0.02 Ry. Increasing these cutoffs resulted only in minor changes to the computed activation energies, 
see Table S1. We also tested the role of adding a van der Waals correction using both Grimme's approach [41] and the exchange-hole dipole moment (XDM) dispersion model [42, 43], see Table S2. We find that this contribution leads to changes in activation energies of around $0.1 \mathrm{eV}$, a value small enough to ensure that none of the conclusions presented here are affected. It does not change the picture presented here and will not be discussed further. Five-layer silver slabs were used with the computed lattice constant (4.15 ̊) and a Monkhorst-Pack k-point mesh equivalent to (12x12) for the (1x1) surface unit cell. A p(4x4) cell was employed for the $\operatorname{Ag}(111)$ and a $\mathrm{p}(2 \times 2)$ cell for the $\mathrm{Ag}(110)$ reconstruction. The minimum energy paths were computed using the climbing image nudged elastic band (NEB) method with the bottom two layers of the slabs held fixed. Each path was discretized into 8 images with a single transition state separating local minima. We considered the transition states to be converged when the force on the climbing images was less than $0.05 \mathrm{eV} / \AA$ and the change in energy simultaneously was less than $10^{-3} \mathrm{eV}$. We ensured the NEB calculations converged to the transition states through normal mode analyses. Core level binding energies were computed using the $\triangle \mathrm{SCF}$ procedure to capture initial and final state effects [38]. The relative values computed in this way were shifted to absolute values using a reference state calculation on a $(2 \times 2 \times 2)$ cell of $\mathrm{Ag}_{2} \mathrm{CO}_{3}$ and the corresponding measured binding energies [39]. We have previously found this approach to give computed binding energies to within $\pm 0.3 \mathrm{eV}$ of experimental values [15]. For a full description of our approach see Reference [15].

We tested the theoretical predictions for the $\mathrm{p}(4 \mathrm{x} 4)$ reconstruction through temperature programmed reaction (TPR). The experiments were carried out in a combined ultra-high vacuum (UHV)/ambient pressure system described in detail elsewhere [46]. The sample was cleaned by multiple cycles of $\mathrm{Ar}^{+}$sputtering and subsequent heating to $775 \mathrm{~K}$. To avoid high oxygen doses 
the clean $\operatorname{Ag}(111)$ surface was dosed with $\sim 600 \mathrm{~L} \mathrm{NO}_{2}$ at $500 \mathrm{~K}$ to produce the $\mathrm{p}(4 \mathrm{x} 4)$ reconstruction following an established procedure [47]. We know from LEED performed after earlier experiments that this procedure leads to the formation of the oxygen induced $\mathrm{p}(4 \mathrm{x} 4)$ reconstruction, which we verified by an XPS O 1s binding energy (BE) of $528.3 \mathrm{eV}$. XPS measurements were carried out with a monochromatic Al K $\alpha$ source (Omicron XM 1000) and a hemispherical analyzer (SPECS Phoibos 100). The energy axis of the spectra was calibrated using the $\mathrm{Ag} 3 \mathrm{~d}_{5 / 2}$ peak with a $\mathrm{BE}$ of $368.25 \mathrm{eV}$. After preparation of the $\mathrm{p}(4 \mathrm{x} 4)$ reconstruction the sample was dosed with $54000 \mathrm{~L} \mathrm{C}_{2} \mathrm{H}_{4}$ at room temperature and investigated with TPR and XPS. In a second set of experiments ethylene was dosed at $0.1 \mathrm{mbar}$ for $10 \mathrm{~min}$ at $298 \mathrm{~K}$. For the TPR experiment, the sample was heated at $0.8 \mathrm{~K} / \mathrm{s}$. Products were measured by a quadrupole mass spectrometer (Pfeiffer Prisma QMS 200 M2).

\section{Results}

\section{Ethylene oxidation on the $p(2 x 1)$-reconstructed Ag(110) surface}

Atomically adsorbed oxygen on the $\operatorname{Ag}(110)$ is populated with a sticking coefficient of approximately $2 \times 10^{-3}$ at room temperature, giving rise to a $\mathrm{p}(\mathrm{N} \times 1)$, so-called added-row reconstruction, where $\mathrm{N}$ ranges from 2-7 [48]. At $423 \mathrm{~K}$ this relatively high sticking probability allows the $\mathrm{p}(2 \mathrm{x} 1)$ reconstruction to be formed at pressures as low at $10^{-4} \mathrm{mbar}$ [12]. Furthermore, this reconstruction is known to be present on $\mathrm{Ag}(110)$ single crystals after ethylene epoxidation at $\sim 500 \mathrm{~K}$ with $\mathrm{O}_{2}$ pressures from 5-200 mbar [21]. The ease with which the $\mathrm{p}(2 \mathrm{x} 1)$ reconstruction can be prepared has allowed it to be thoroughly characterized $[15,49,50]$. This fact, along with its ubiquity, makes the $\mathrm{p}(2 \mathrm{x} 1)$ added-row reconstruction a good system with which to begin our current study. 
The name, added-row, stems from the formation mechanism according to which adsorbed $\mathrm{O}$ and $\mathrm{Ag}$ atoms condense on the terraces to form $\mathrm{Ag}-\mathrm{O}$ chains along the [001] directions of the surface with (2x1) periodicity [51], as shown in Figure 1. This bonding topology is reminiscent of the linear Ag-O bonding in the bulk oxide, $\mathrm{Ag}_{2} \mathrm{O}$, [15] and leads to the formation of $\mathrm{Ag}^{\delta+}$ in the added rows, as evidenced by their computed Ag3d shift (including final state effects) of -0.4 $\mathrm{eV}$ with respect to bulk silver. The charge transfer to oxygen also leads to a measured/computed oxygen $\mathrm{O} 1 \mathrm{~s}$ binding energy of approximately $528.3 \mathrm{eV}$, which is less than that seen in bulk $\mathrm{Ag}_{2} \mathrm{O}(529.2 \mathrm{eV})$ [15], indicating that the Ag-O bonding is partially ionic in this system.

Computationally we find that ethylene adsorbs on the $\mathrm{Ag}^{\delta+}$ site in the added rows, which is the first step in the oxidation path shown in Figure 1. Ethylene adsorption on the $\mathrm{Ag}^{\delta+}$ site, labeled (1) in Figure 1, is associated with $0.11 \mathrm{eV}$ drop in energy. (For convenience the energies along the minimum energy paths are collected in Table 1.) Consistent with this low heat of adsorption is a negligible increase in a C-C bond length, from $1.33 \AA$ in the gas phase to $1.34 \AA$ when adsorbed, in agreement previous NEXAFS measurements that indicated ethylene adsorbs by transferring $\pi$ density to $\mathrm{Ag}^{\delta+}[52]$.

In the second elementary step of Figure 1 adsorbed ethylene reacts with an oxygen atom from the added row to form an OMC producing state (2) in the figure. The activation energy associated with this step is $0.44 \mathrm{eV}$, and the formation of the $\mathrm{OMC}$ is accompanied by a $0.17 \mathrm{eV}$ drop in energy with respect to the adsorbed ethylene. Inspection of the figure reveals that the OMC is highly twisted, thereby allowing the linear Ag-O bonding motif of the added rows to be maintained. This twisting can be seen to result in a staggered conformation for the hydrogen atoms in the $\mathrm{OMC}$, with an O-C-C-Ag dihedral angle of $76^{\circ}$. There is also a reduction in C-C bond order, resulting in the elongation of the C-C bond to $1.51 \AA$. 

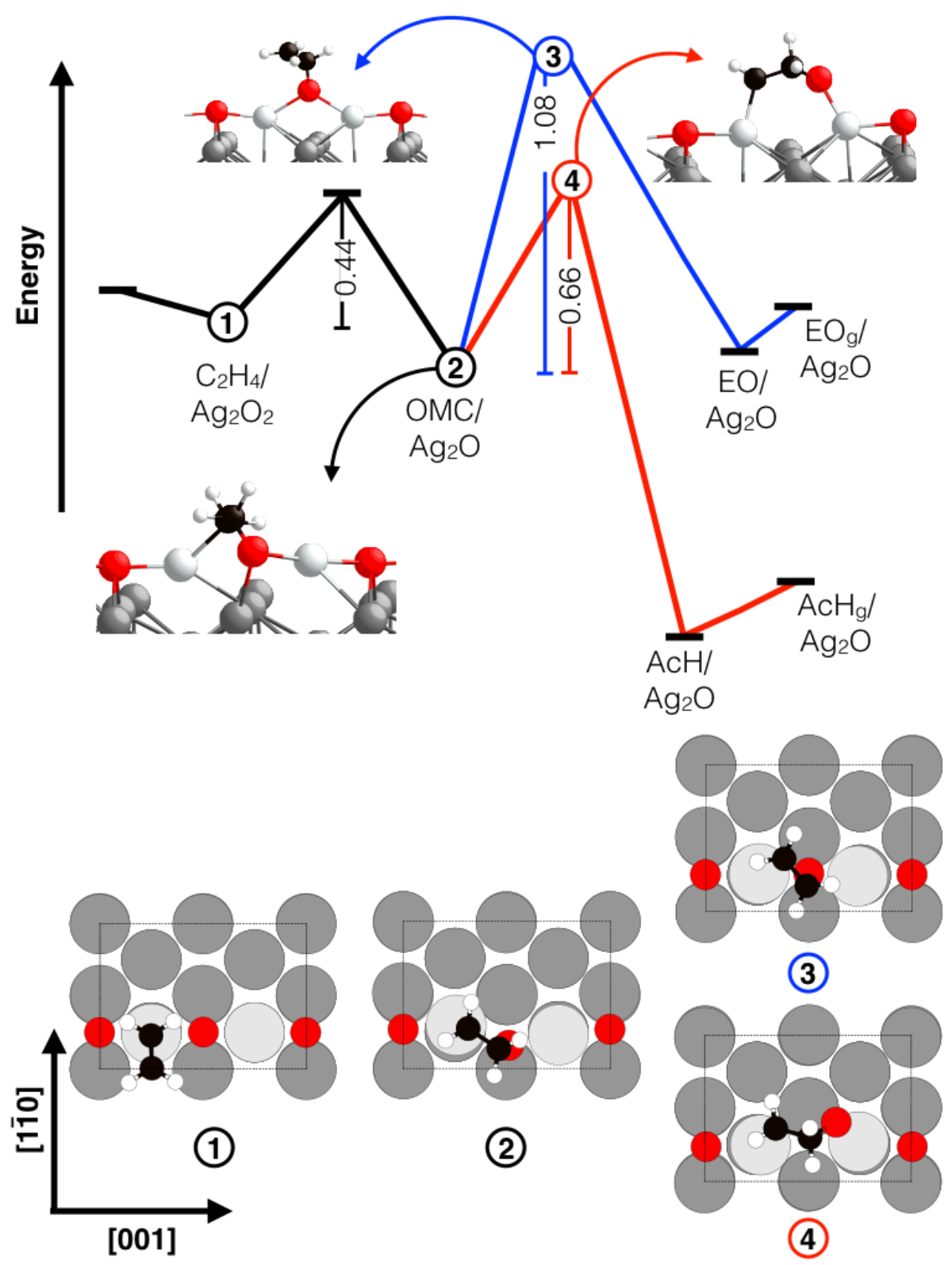

(4)

Figure 1: The minimum energy path computed for reaction of ethylene with oxygen in the $\mathrm{p}(2 \mathrm{x} 1)$ reconstruction on the $\mathrm{Ag}(110)$ surface through the OMC mechanism. The silver in the added row are light gray, the underlying silver are dark gray, oxygen are red, carbon are black, and hydrogen are white. Structure (1) shows the adsorbed ethylene, (2) the OMC intermediate, (3) the transition state leading to $\mathrm{EO}$, and (4) the transition state leading to $\mathrm{AcH}$. The activation energies for the elementary steps are given in $\mathrm{eV}$. See Table 1 for other energies. 
Table 1: Computed adsorption energies $\left(E_{a d s}\right)$, with respect to gas phase $\mathrm{C}_{2} \mathrm{H}_{4}$ and the unmodified surface reconstructions, of the partial oxidation intermediates on the reconstructed $\operatorname{Ag}(110)$ and $\operatorname{Ag}(111)$ surfaces along with their corresponding activation energies $\left(E_{a}\right)$. The formation energy $\left(E_{f}\right)$ of the products is also shown with the same energy reference. The two sets of energies for $\mathrm{AcH}$ formation for the $\mathrm{Ag}(111)$ surface refer to the two pathways discussed in the text. The states corresponding to the labels in Figures 1 and 3 are also listed. All values are reported in $\mathrm{eV}$.

\begin{tabular}{|l|l|l|l|l|l|l|l|}
\hline system & $\begin{array}{l}E_{a d s}\left(\mathrm{C}_{2} \mathrm{H}_{4}\right) \\
\text { State 1 }\end{array}$ & $E_{a}(\mathrm{OMC})$ & $E_{a d s}(\mathrm{OMC})$ & $E_{a}(\mathrm{EO})$ & $E_{f}(\mathrm{EO})$ & $E_{a}(\mathrm{AcH})$ & $E_{f}(\mathrm{AcH})$ \\
State 2 & State 3 & & State 5 (4) & \\
\hline $\begin{array}{l}\mathrm{Ag}(110)- \\
\mathrm{p}(2 \mathrm{x} 1)\end{array}$ & -0.11 & 0.44 & -0.28 & 1.08 & -0.35 & 0.66 & -1.31 \\
\hline $\begin{array}{l}\mathrm{Ag}(111)- \\
\mathrm{p}(4 \mathrm{x} 4)\end{array}$ & -0.08 & 0.38 & -0.03 & 0.66 & -0.16 & 0.29 & -1.30 \\
\hline
\end{tabular}

Once the $\mathrm{OMC}$ has formed it can isomerize to $\mathrm{EO}$ and $\mathrm{AcH}$, as has been calculated for ethylene epoxidation with adsorbed atomic oxygen on the unreconstructed surface [28-33]. However, unlike adsorbed atomic oxygen on the unreconstructed surface, where the EO and AcH activation energies are nearly equal, the barrier to EO formation is significantly higher than that associated with $\mathrm{AcH}$ formation on this reconstructed $\mathrm{Ag}(110)$ surface, $1.08 \mathrm{eV}$ and $0.66 \mathrm{eV}$, respectively. This can be rationalized by the fact that the hydrogen atoms in the OMC have a staggered geometry, which facilitates the hydrogen shift from $\mathrm{C}_{1}$ (carbon bound to $\mathrm{O}$ in the $\mathrm{OMC}$ ) to $\mathrm{C}_{2}$ (carbon not bound to $\mathrm{O}$ in the $\mathrm{OMC}$ ) [53]. Thus, assuming similar pre-factors for the two competing rearmaments, our calculations predict that, with an EO selectivity on the order of 
$10^{-4}$ at $500 \mathrm{~K}$, the oxygen-induced $\mathrm{p}(2 \times 1)$ reconstruction on the $\operatorname{Ag}(110)$ surface will produce only AcH through the OMC mechanism. However, the aldehyde is not the terminal product on this surface. Instead, AcH has been shown to rapidly convert into acetate on an oxygen-covered $\operatorname{Ag}(110)$ surface [54], which, under epoxidation conditions, further reacts with adsorbed oxygen to produce $\mathrm{CO}_{2}[55]$. The finding that the oxygen-induced $\mathrm{p}(2 \mathrm{x} 1)$ reconstruction is incapable of producing EO is in agreement with previous experimental work [21].

Ethylene oxidation on the $p(4 x 4)$ reconstruction of $A g(111)$

Though the finding that the oxygen-induced $\mathrm{p}(2 \mathrm{x} 1)$ reconstruction on silver strongly favors AcH production through an $\mathrm{OMC}$ mechanism, and ultimately combustion, is interesting, the analysis of temperature programed desorption (TPD) data suggests much of the oxygen on high surface area catalysts is adsorbed on close-packed faces [23]. And while the oxygen-induced reconstructions on the $\mathrm{Ag}(110)$ surface appear oxidic due to their linear Ag-O-Ag bonding motif, the oxygen-induced reconstructions on the $\operatorname{Ag}(111)$ surface are unlike any known bulk phases [16-19]. This novel bonding may also lead to unique chemistry.

The $\mathrm{p}(4 \times 4)$ oxygen-induced reconstruction is the prototype and most well-studied member [1618] of a family of similar surface reconstructions on the $\operatorname{Ag}(111)$ surface [19]. This structure is now known to be comprised of two $\mathrm{Ag}_{6}$ triangles in the $(4 \mathrm{x} 4)$ cell with a pair of oxygen atoms shared between each $\mathrm{Ag}_{6}$ edge as shown in Figure 2 [15-19]. In our $0 \mathrm{~K}$ DFT calculations one of the oxygen atoms in each pair sits $0.55 \AA$ above the $\mathrm{Ag}_{6}$ triangles while the other member of the pair is $0.24 \AA$ below the triangles. This difference in oxygen atom height leads to the azimuthal rotation of the $\mathrm{Ag}_{6}$ triangles indicated by way of the curled arrows in Figure 2. The corners of neighboring triangles are separated by $3.06 \AA$, atoms labeled 1 and 2 , when the shared oxygen 
atom is above the $\mathrm{Ag}_{6}$ plane and is $3.76 \AA$, atoms labeled 3 and 4, when the oxygen sits below the $\mathrm{Ag}_{6}$ plane. However, this clockwise and counterclockwise rotation of the silver triangles is thought to change dynamically already at room temperatures [16].

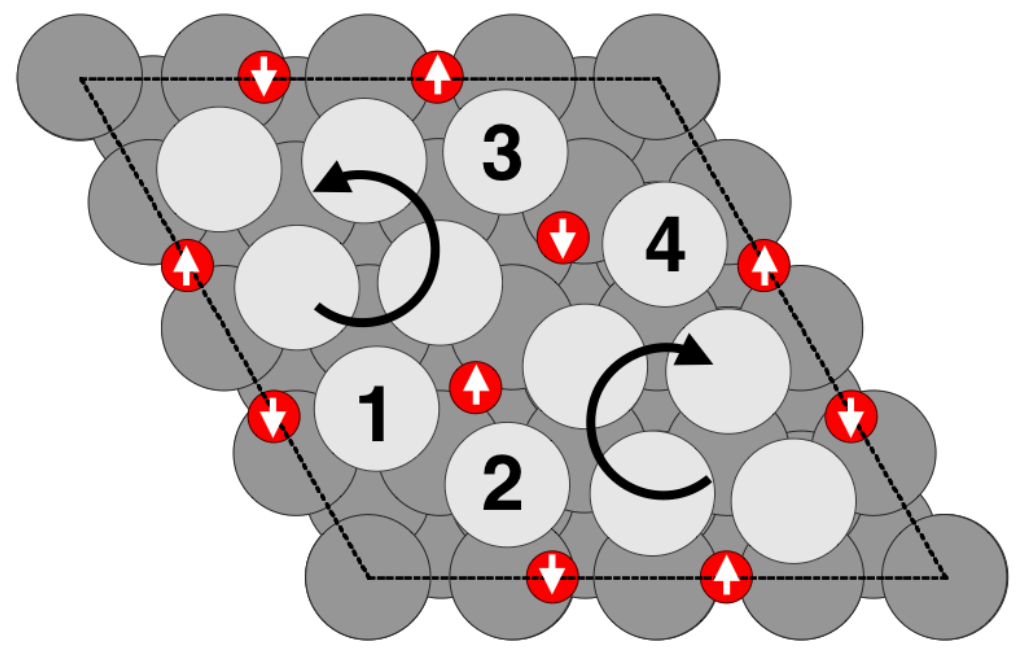

Figure 2: The $p(4 \times 4)$ oxygen-induced reconstruction of the $\operatorname{Ag}(111)$ surface. The black arrows indicate the azimuthal rotation of the $\mathrm{Ag}_{6}$ triangles. The oxygen atoms are colored red, the silver atoms in the $\mathrm{Ag}_{6}$ triangles are light gray, and the underlying silver is colored dark gray. The white arrows on the oxygen atoms indicate whether they lie above (up arrows) or below (down arrows) the plane of the $\mathrm{Ag}_{6}$ triangles.

Despite the $\mathrm{p}(4 \mathrm{x} 4)$ reconstruction's dissimilarity to the bulk oxide, $\mathrm{Ag}_{2} \mathrm{O}$, the $\mathrm{Ag}-\mathrm{O}$ bonding also leads to the formation $\mathrm{Ag}^{\delta+}$ in the silver triangles, as indicated by a $\mathrm{Ag} 3 \mathrm{~d}$ shift of between $0.3 \mathrm{eV}$ and $-0.6 \mathrm{eV}$ relative to the bulk metal [56]. And, as with the $\mathrm{Ag}^{\delta+}$ in the oxygen-induced reconstruction on the (110) surface, on the (111) surface this positive charge on Ag facilitates ethylene adsorption. The computed favored adsorption site, see Figure 3 state (1), agrees with previous STM measurements [11], though it should be noted that these measurements were originally interpreted with a since disproven $2 \mathrm{D}$ oxide-like model of the $\mathrm{p}(4 \mathrm{x} 4)$ structure. While 
our computed adsorption site on the $\mathrm{Ag}_{6}$ triangle is in agreement with previous experiments, the interaction with the correct model of the $\mathrm{p}(4 \mathrm{x} 4)$ reconstruction is weaker than what was predicted on the early oxide-like model [11]. In our case ethylene adsorption on the favored $\mathrm{Ag}^{\delta+}$ site is $0.08 \mathrm{eV}$ exothermic and is accompanied by a lengthening of the $\mathrm{C}-\mathrm{C}$ bond to $1.34 \AA$, similar to the oxygen-reconstructed $\operatorname{Ag}(110)$ surface previously discussed. Again, the energies along the minimum energy paths are summarized in Table 1 . For comparison, the adsorption energy on the disproven oxide-like model of the $\mathrm{p}(4 \mathrm{x} 4)$ reconstruction was previously computed to be $0.39 \mathrm{eV}$ and the C-C bond length $1.37 \AA$. We did not consider this model in our calculations and refer the interested reader to Reference [11].

We find that, once adsorbed, the ethylene can react with the oxygen lying above the plane to form an $\mathrm{OMC}$ by surmounting a barrier of only $0.38 \mathrm{eV}$. This elementary step is weakly endothermic, raising the energy of the system by $0.05 \mathrm{eV}$ with respect to the adsorbed ethylene. (Note that reaction with the oxygen below the plane increases the energy of the system a further $0.29 \mathrm{eV}$ and will not be considered further.) The resultant intermediate, and its position along the reaction path, is shown in Figure 3 state (2). A more detailed view of the OMC is shown in Figure 4. As on the $\mathrm{Ag}(110)$ surface, the C-C bond in the OMC is stretched to $1.50 \AA$. However, unlike on the $\operatorname{Ag}(110)$ surface, the OMC on the $\mathrm{p}(4 \mathrm{x} 4) / \operatorname{Ag}(111)$ surface is characterized by nearly eclipsed hydrogen atoms. The two symmetry unique pairs of cis-hydrogen atoms have $\mathrm{H}-$ C-C-H dihedral angles of $1^{\circ}$ and $12^{\circ}$, see Figure 4 . For simplicity we will refer to these as the $1^{\circ}$ eclipsed and $12^{\circ}$-staggered hydrogen atoms, respectively. 


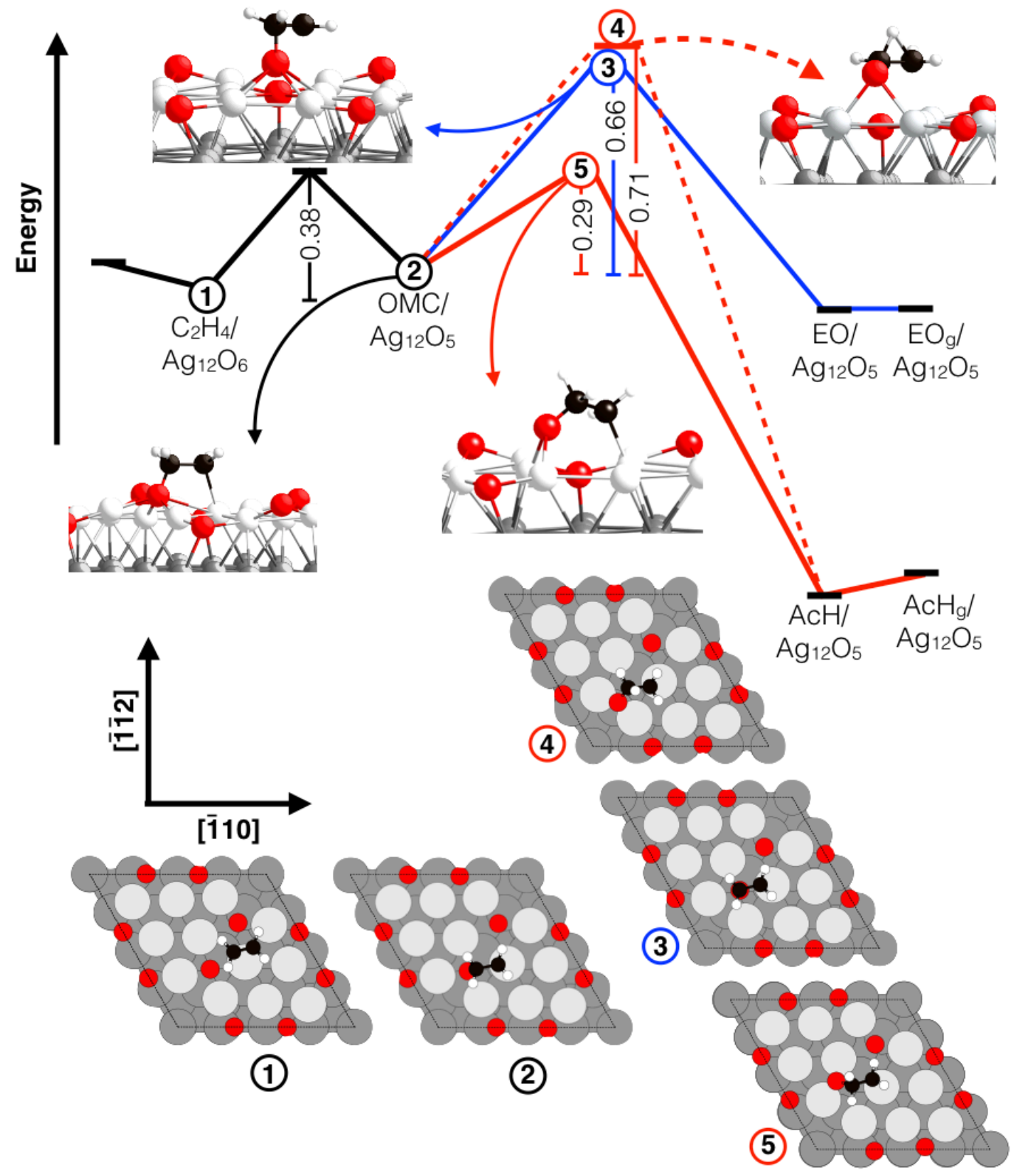

Figure 3: Minimum energy paths for $\mathrm{AcH}$ and $\mathrm{EO}$ formation on the $\mathrm{p}(4 \times 4)$ oxygen induced reconstructed $\operatorname{Ag}(111)$ surface through the OMC mechanism. The oxygen atoms are colored red, the silver atoms in the $\mathrm{Ag}_{6}$ triangles are light gray, the underlying silver is colored dark gray, carbon atoms are black, and oxygen atoms are white. State (1) shows the adsorbed ethylene, (2) the OMC, (3) the transition state to EO, (4) the transition state to AcH associated with the 
eclipsed hydrogen, (5) the transition state to $\mathrm{AcH}$ associated with the staggered hydrogen. The activation energies for the elementary steps are given in $\mathrm{eV}$. See Table 1 for other energies.
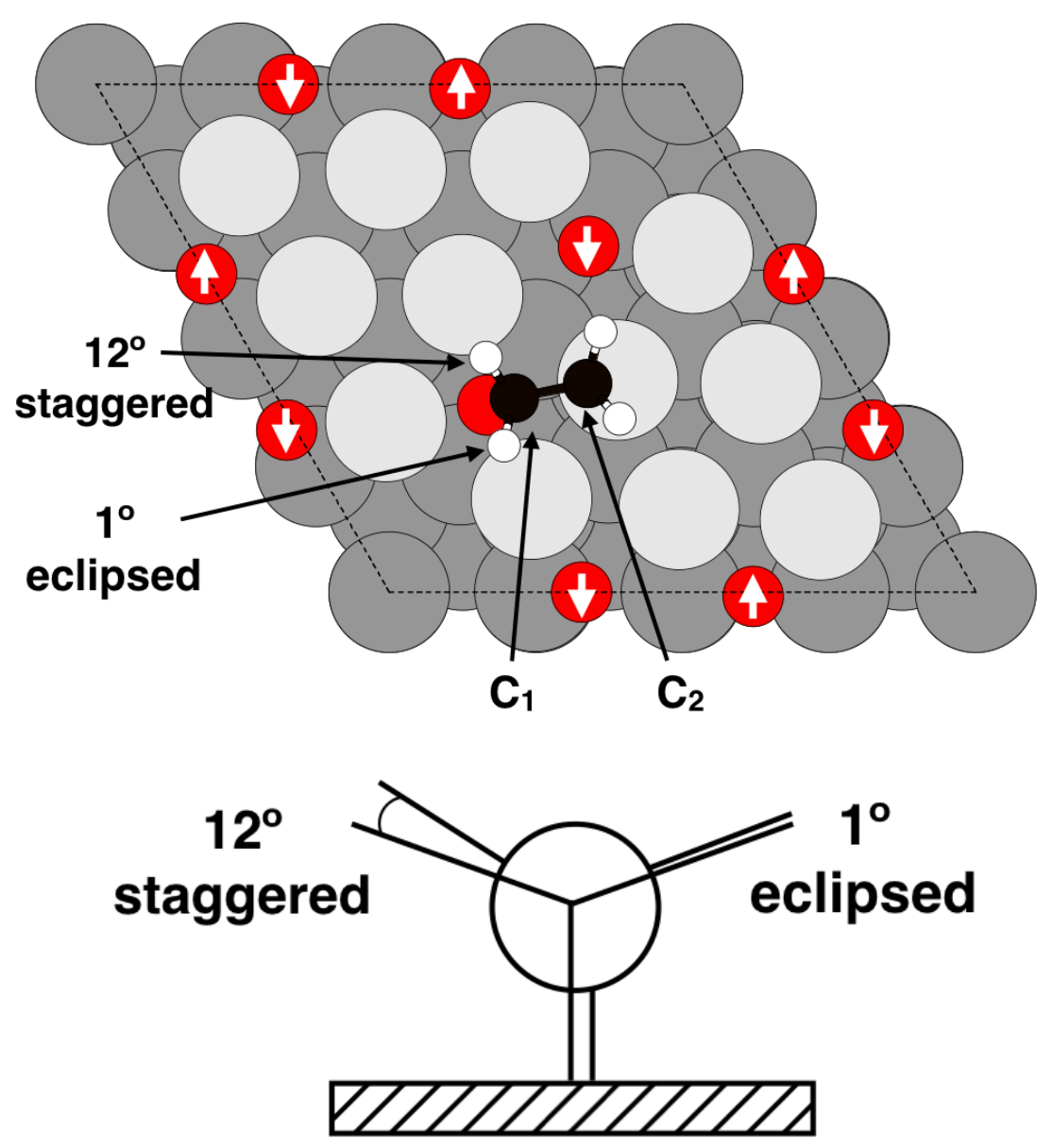

Figure 4: Ball and stick model of the $\mathrm{OMC}$ on the $\mathrm{p}(4 \times 4)$ reconstruction on the $\mathrm{Ag}(111)$ surface [the same as state (2) in Figure 3] with the two types of hydrogen and carbon atoms labeled (top). The coloring is identical to Figure 3. Arrows have also been placed on the oxygen atoms to denote whether they lie above (up arrow) or below (down arrow) the plane of the $\mathrm{Ag}_{6}$ triangles. The oxygen in the $\mathrm{OMC}$ lies above the $\mathrm{Ag}_{6}$ triangles. Schematic of the $\mathrm{OMC}$ confirmation viewed along the C-C bond axis (bottom). 
From the results on the (110) surface, and those presented in Ref. [53], we might expect the $\mathrm{AcH} / \mathrm{EO}$ branching ratio to favor EO on the (111) surface when the shift of a hydrogen atom from $\mathrm{C}_{1}$ (near the $\mathrm{O}$ atom, see Figure 4 ) to $\mathrm{C}_{2}$ (see Figure 4) involves the $1^{\circ}$-eclipsed hydrogen in the OMC on the $\mathrm{p}(4 \mathrm{x} 4) / \mathrm{Ag}(111)$ surface. Comparing states (3) and (4) in Figure 3 reveals this is the case. The figure shows the sole minimum energy path we find for ring closure and EO formation through state (3), with a barrier of $0.66 \mathrm{eV}$ and a $-0.13 \mathrm{eV}$ heat of reaction for the elementary step. The transition state for the $C_{1}$ to $C_{2}$ shift of the $1^{\circ}$-eclipsed hydrogen atom, shown in state (4), is marginally higher, at $0.71 \mathrm{eV}$. This elementary step for $\mathrm{AcH}$ formation is $1.26 \mathrm{eV}$ exothermic with respect to the OMC. Here, as with the $\mathrm{Ag}(110)$ surface, the difference in activation energies can be rationalized by the OMC's propensity towards the $C_{1}$ to $C_{2}$ hydrogen shift. However, the reconstructed $\operatorname{Ag}(111)$ surfaces differ from their $\operatorname{Ag}(110)$ counterparts in that the former have been argued to be dynamic, with the $\mathrm{Ag}_{6}$ triangles thought to rotate between equivalent positions, as indicated in Figure 2 [17]. We find that this dynamic behavior imparts an unexpected chemistry when examining the $\mathrm{C}_{1}$ to $\mathrm{C}_{2}$ shift of the $12^{\circ}$ staggered hydrogen.

State (5) in Figure 3, which is reproduced in Figure 5 for clarity, shows the transition state for the $\mathrm{C}_{1}$ to $\mathrm{C}_{2}$ shift of the $12^{\circ}$-staggered hydrogen atom in the $\mathrm{OMC}$. The activation energy for this elementary step is only $0.29 \mathrm{eV}$, significantly less than that observed for other OMC decomposition pathways on silver [33]. We find that the barrier is reduced by the dynamics of the reconstruction. At the transition state these dynamics allow the $\mathrm{Ag}_{6}$ triangle labeled with an arrow in Figure 5 to rotate $\sim 3^{\circ}$ counterclockwise with respect to its initial position [state (2) in Figure 3]. This rotation leads to a reduction in the Ag-Ag distance of the atoms labeled 1 and 2 in 
Figure 5 from $3.32 \AA$ in the OMC [state (2) in Figure 3] to $2.86 \AA$, slightly less than the DFTcalculated Ag bulk interatomic distance of $2.94 \AA$.

The $\mathrm{Ag}_{6}$ triangle rotation and the $\mathrm{Ag}-\mathrm{Ag}$ bond formation significantly reduce the energy at the transition state. To quantify this reduction we performed a NEB calculation wherein only the C, $\mathrm{H}$, and $\mathrm{O}$ atoms of the $\mathrm{OMC}$ were allowed to relax during $\mathrm{AcH}$ formation. The remaining $\mathrm{Ag}$ and $\mathrm{O}$ atoms were linearly transformed from their initial to final state positions along the NEB path. Suppressing the substrate rotation in this way increased the activation energy to $0.88 \mathrm{eV}$ compared to $0.29 \mathrm{eV}$ for the dynamic surface. Thus, if similar pre-factors for $\mathrm{AcH}$ and $\mathrm{EO}$ isomerization are assumed, the dynamic nature of the $\mathrm{p}(4 \mathrm{x} 4)$ structure makes it selectively produce $\mathrm{AcH}$, with an EO selectivity on the order of $10^{-4}$ at $500 \mathrm{~K}$. However, as on the (110) surface, $\mathrm{AcH}$ is not expected to be the terminal product on the $\mathrm{p}(4 \mathrm{x} 4)$ reconstruction $[57,58]$.

Although we made no attempt to compute the mechanism of the rapid combustion chemistry of $\mathrm{AcH}$ on the $\mathrm{p}(4 \mathrm{x} 4)$ reconstruction, from previous high resolution reflection absorption infrared spectroscopy (RAIRS) studies we know that at saturation coverage this AcH will be completely converted into adsorbed acetate by $220 \mathrm{~K}$ under UHV and to $\mathrm{CO}_{2}$ by $450 \mathrm{~K}$ [57]. By analogy with the (110) surface it appears plausible that, at lower coverage, acetate may also react with adsorbed oxygen to produce formate at temperatures significantly ( 200 K) less than the UHV decomposition temperature of acetate [55]. Formate, however, also decomposes to form $\mathrm{CO}_{2}$, albeit at $350 \mathrm{~K}[58]$, indicating that regardless of the exact pathway the terminal product for AcH under epoxidation conditions on this surface is $\mathrm{CO}_{2}$. Thus, as with the $\mathrm{p}(2 \mathrm{x} 1)$ reconstruction on the $\operatorname{Ag}(110)$ surface, we expect the $\mathrm{p}(4 \mathrm{x} 4)$ reconstruction on the $\mathrm{Ag}(111)$ surface to selectively produce $\mathrm{CO}_{2}$. 


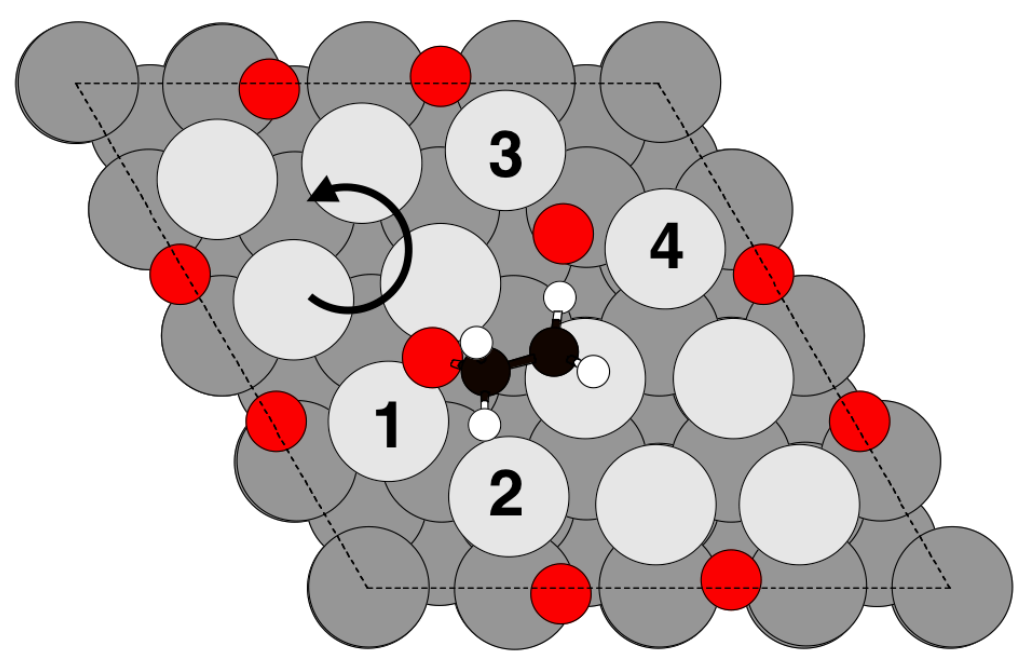

Figure 5: Transition state for the barrier pathway to $\mathrm{AcH}$ on the $\mathrm{p}(4 \mathrm{x} 4)$ reconstruction on the $\operatorname{Ag}(111)$ surface through the $C_{1}$ to $C_{2}$ shift of the $12^{\circ}$-staggered hydrogen. The coloring is identical to Figure 3. The rotation of the surface $\mathrm{Ag}_{6}$ triangle is indicated by an arrow. An enlarged side view of this structure is given in the supporting information.

The computational prediction that neither surface reconstruction can produce EO through the OMC mechanism may come as a surprise considering that the $\mathrm{p}(4 \mathrm{x} 4)$ reconstruction has often been viewed as a prototypical active surface oxide [16] and there is spectroscopic evidence that this type of oxygen is present under reaction conditions $[12,15]$. To validate our theoretical predictions we performed a series of TPR experiments on an $\operatorname{Ag}(111)$ single crystal.

After preparing the single crystal with $\mathrm{NO}_{2}$ we verified that the $\mathrm{p}(4 \mathrm{x} 4)$ reconstruction was present by XPS (see Figure 6). There were also traces of re-adsorbed $\mathrm{NO} / \mathrm{NO}_{2}$ present, as can be seen by the small peak at $531.65 \mathrm{eV}$, characterizing $\mathrm{NO}$ on the O-covered surface [59]. We then dosed ethylene at room temperature. At this temperature we predict from our DFT results that the ethylene will adsorb on the $\mathrm{Ag}^{\delta+}$ sites, as in state (1) of Figure 3, and surmount the small (0.29 
$\mathrm{eV}$ ) barrier to form $\mathrm{AcH}$. The aldehyde is then expected to rapidly convert into acetate [57] or formate [58] and eventually $\mathrm{CO}_{2}$ near room temperature [57, 58].
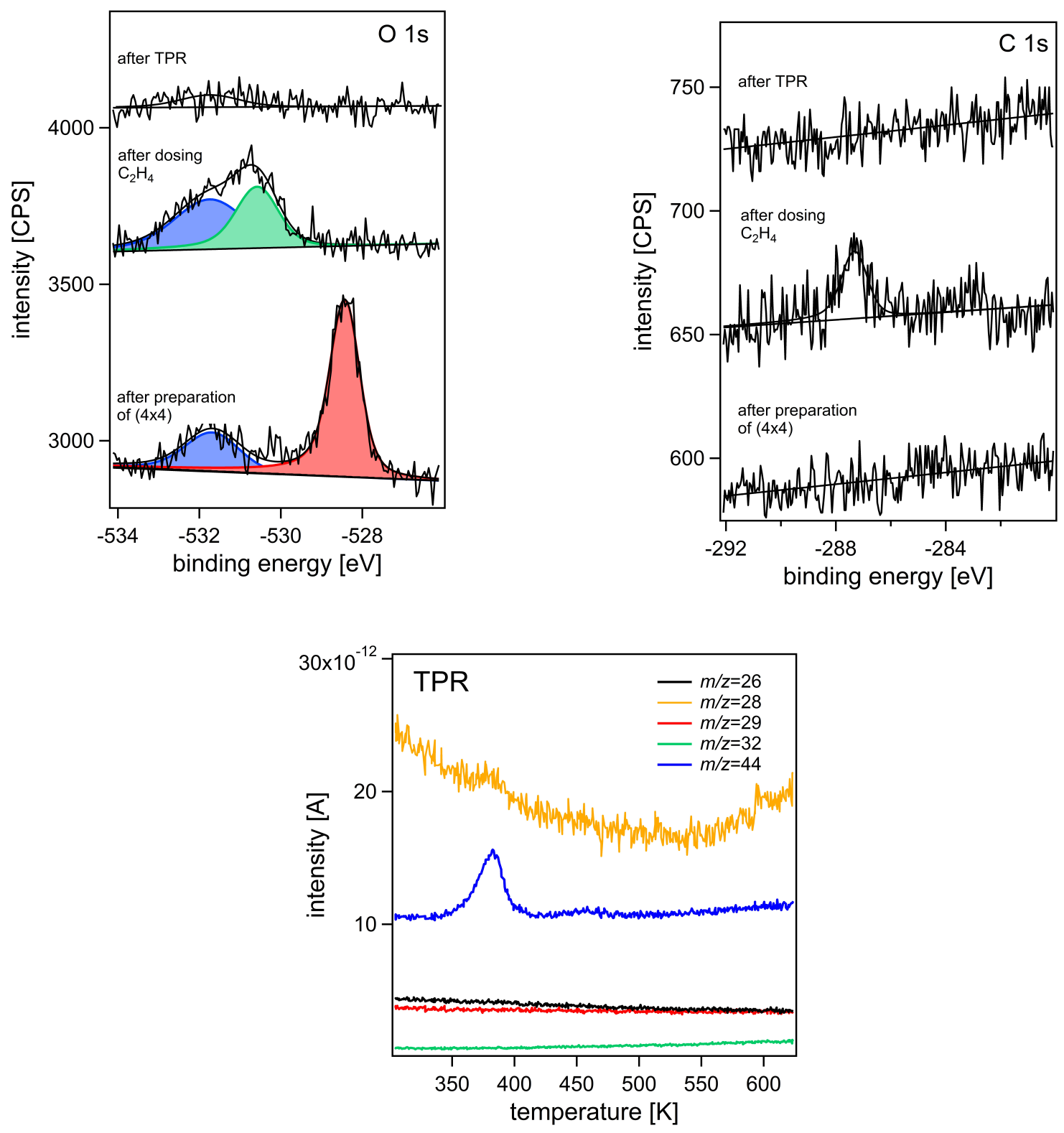

Figure 6: $O$ 1s spectra (left) of the as prepared $p(4 \times 4)$ reconstruction, the surface after ethylene dosing, and the $\operatorname{Ag}(111)$ surface after the TPR experiment. The corresponding C 1s spectra are also shown (right). The small peak in the $\mathrm{C} 1 \mathrm{~s}$ spectrum at $283 \mathrm{eV}$ after ethylene dosing indicates the presence of some additional form of reduced carbon. For better visibility the spectra were 
displaced on the intensity axis. QMS signals obtained during the TPR experiment (bottom). The noise of the $m / z=28$ trace comes from the subtraction of a high background signal.

In support of this assertion, the XP spectra after dosing $\mathrm{C}_{2} \mathrm{H}_{4}$ shows that the $\mathrm{p}(4 \mathrm{x} 4)$ reconstruction has vanished and that a new peak appears. This peak can be deconvoluted into two peaks, indicating the presence of two species, readsorbed $\mathrm{NO} / \mathrm{NO}_{2}$ at $531.65 \mathrm{eV}$ and a second species at $530.5 \mathrm{eV}$. Inspection of the $\mathrm{C} 1 \mathrm{~s}$ spectrum reveals an oxidized carbon species with a $\mathrm{BE} 287.3 \mathrm{eV}$ suggesting the oxygen species with an $\mathrm{O} 1 \mathrm{~s} \mathrm{BE}$ of $530.5 \mathrm{eV}$ is bound to carbon. Our core level BE calculations (see Table 2) reveal that formate and acetate are the most likely of the plausible $\mathrm{H}_{\mathrm{x}} \mathrm{C}_{\mathrm{y}} \mathrm{O}_{\mathrm{z}}$ species that could give rise to these $\mathrm{C} 1 \mathrm{~s}$ and $\mathrm{O} 1 \mathrm{~s}$ features, with formate giving the best agreement with both the $\mathrm{C} 1 \mathrm{~s}$ and $\mathrm{O} 1 \mathrm{~s}$ energies. Though the statistics of the carbon spectra are quite poor because of the low cross-section of the $\mathrm{C}$ 1s signal with $\mathrm{Al} \mathrm{K \alpha}$ irradiation (0.013 for $\mathrm{C} 1 \mathrm{~s}, 0.04$ for $\mathrm{O} 1 \mathrm{~s})$ [60], the cross section-corrected ratio $(\mathrm{O} 1 \mathrm{~s} 530.5$ $\mathrm{eV} / \mathrm{C} 1 \mathrm{~s} 287.3 \mathrm{eV}$ ) is 2.5 , implying that primarily a $\mathrm{H}_{\mathrm{x}} \mathrm{CO}_{2}$ species like formate is present after ethylene dosing. Such a formate species is expected to decompose into $\mathrm{CO}_{2}$ at $\sim 350 \mathrm{~K}$ [58] . Thus, in a second experiment we heated the likewise prepared sample at $0.8 \mathrm{~K} / \mathrm{s}$ directly after ethylene dosing to desorb the products that were monitored by QMS. 
Table 2: Computed core level binding energies of oxidized carbon species on the $\mathrm{p}(4 \mathrm{x} 4)$ reconstruction on the $\operatorname{Ag}(111)$ surface. All values are in $\mathrm{eV}$ and were computed using the $\Delta \mathrm{SCF}$ method to include both initial and final state effects. In cases where there are multiple atoms of the same type all respective core level binding energies are listed.

\begin{tabular}{|l|l|l|}
\hline System & $\mathbf{O} 1 \mathbf{s}[\mathbf{e V}]$ & $\mathbf{C} \mathbf{1 s}[\mathbf{e V}]$ \\
\hline $\mathrm{C}_{2} \mathrm{H}_{4}$ & -- & $284.8,284.8$ \\
\hline $\mathrm{OMC}$ & 529.9 & $285.8,283.2$ \\
\hline $\mathrm{OH}$ & 530.5 & -- \\
\hline $\mathrm{AcH}$ & 531.2 & $286.5,286.2$ \\
\hline Acetate & $530.8,530.7$ & $287.7,285.8$ \\
\hline Formate & $530.9,530.9$ & 287.5 \\
\hline $\mathrm{CO}_{2}$ & $534.1,534.1$ & 289.6 \\
\hline Measured & $531.6,530.5$ & 287.3 \\
\hline
\end{tabular}

Typically in this type of TPR experiment the presence of EO is determined by the mass fragment $m / z=29$ amu. However, owing to the challenges associated with discerning partial oxidation products from the natural $2.2 \%{ }^{12} \mathrm{C}^{13} \mathrm{CH}_{4}$ isotope in ethylene using $\mathrm{m} / \mathrm{z}=29$ amu on the $\operatorname{Ag}(111)$ surface [61], we monitored both $m / z=29$ amu and $m / z=26 \mathrm{amu}$. Doing so allows us to rule out the possibility of ethylene desorption as a source of $m / z=29 \mathrm{amu}$. We also monitored the $\mathrm{CO}_{2}$ mass $m / z=44 \mathrm{amu}$, which has cross sensitivity with the primary EO mass, but, as we have a secondary means of EO detection, this cross sensitivity is not problematic. Finally, to see if any oxygen remains unreacted we measured $\mathrm{m} / \mathrm{z}=32 \mathrm{amu}$. 
The QMS results from the TPR experiment are shown in Figure 6. We saw that $m / z=44$ amu and $m / z=28$ amu show a maximum at approximately $380 \mathrm{~K}$, somewhat higher than the $350 \mathrm{~K}$ measured for formate decomposition on this surface [58]. The intensities are in accordance with the fragmentation pattern of $\mathrm{CO}_{2}$ [61]. In addition, the $m / z=44$ amu showed a very small peak at about $460 \mathrm{~K}$, which is close to the $450 \mathrm{~K}$ previously measured for acetate decomposition on this surface [57], indicating that some acetate may have been present. We interpret these results as the decomposition of formate and acetate and subsequent desorption of $\mathrm{CO}_{2}$. We were, however, unable to detect concomitant desorption of $\mathrm{H}_{2}$ or $\mathrm{H}_{2} \mathrm{O}$.

The measured desorption temperatures of $m / z=44$ amu are in line with those seen during similar TPR experiments on high surface area catalysts [23]. However, unlike results on high surface area catalysts we saw no $\mathrm{m} / \mathrm{z}=29 \mathrm{amu}$ that would indicate partial oxidation products, in support of our theoretical simulations. There was also no peak in the $m / z=32$ amu trace indicating that all the $\mathrm{p}(4 \mathrm{x} 4)$ structure has reacted with ethylene. This observation also rules out the possibility that $\mathrm{CO}_{3}{ }^{2-}$ was present, as it would have desorbed as $\mathrm{CO}_{2}$ and $\mathrm{O}_{2}$. The desorption of the oxygen from the $\mathrm{p}(4 \mathrm{x} 4)$ structure would occur at about $580 \mathrm{~K}[62]$.

The $\mathrm{O} 1 \mathrm{~s}$ and $\mathrm{C} 1 \mathrm{~s}$ spectra recorded after TPR (fig. 6c) show that the $\mathrm{O}$ 1s peak at $528 \mathrm{eV}$ assigned to the oxygen on the reconstructed surface vanished completely and the peaks associated with $\mathrm{H}_{\mathrm{x}} \mathrm{CO}_{2}$ and $\mathrm{NO} / \mathrm{NO}_{2}$ have shrunk substantially. Thus, from these experiments it appears that the oxygen in the $\mathrm{p}(4 \mathrm{x} 4)$ reconstruction is only active in total oxidation. We also performed TPR experiments with higher $\mathrm{C}_{2} \mathrm{H}_{4}$ dosing $(0.1 \mathrm{mbar}$ ethylene for $10 \mathrm{~min})$, which show similar results, although in this case there is an increase in the amount of $m / z=44$ amu desorbing at $475 \mathrm{~K}$, which is consistent with the expected higher initial coverage of AcH (see SI). 


\section{Conclusions}

In summary, we have performed DFT calculations of the reaction of ethylene with oxygen in two well-known surface reconstructions, the $\mathrm{p}(2 \mathrm{x} 1)$ structure on the $\operatorname{Ag}(110)$ and the $\mathrm{p}(4 \mathrm{x} 4)$ structure on the $\operatorname{Ag}(111)$ surfaces. In both cases the calculations predict oxidation can occur through an $\mathrm{OMC}$ intermediate that decomposes into acetaldehyde, which is quickly converted to $\mathrm{CO}_{2}$ on an oxygen-covered silver surface. And though we predict the dynamic nature of the $\mathrm{p}(4 \mathrm{x} 4)$ reconstruction makes it active in room temperature ethylene oxidation, these dynamics alone are not enough to make the surface selective towards ethylene oxide production. TPR experiments of ethylene adsorbed on the oxygen-induced $\mathrm{p}(4 \mathrm{x} 4)$ reconstruction on the $\operatorname{Ag}(111)$ surface confirm these predictions, with ethylene reacting at room temperature to form an adsorbed intermediate that desorbs as $\mathrm{CO}_{2}$ upon heating. Thus, we have demonstrated that, alone, the oxygen-reconstructed silver surfaces that are thermodynamically favored under the oxygen chemical potentials required for ethylene epoxidation cannot produce the epoxide. These findings allow us to shift our focus away from these well-known structures and on to identifying new species and their roles in epoxidation.

Corresponding Author

*Email: trjones@fhi-berlin.mpg.de 


\section{Supporting Information}

TPR results from high pressure experiments, structures of possible reaction intermediates, convergence tests for calculations, computed results with van der Waals (vdW) corrections.

\section{Acknowledgments}

We gratefully acknowledge Höchstleistungsrechenzentrum Stuttgart (HLRS) for generous access to the supercomputer HazelHen through the SEES2 project. T. E. J. acknowledges the Alexander-von-Humboldt foundation for financial support.

\section{References}

1) van Santen, R. A.; de Groot, C.P.M. The Mechanism of Ethylene Epoxidation. J. Catal. 1986, $98,530-539$.

2) van Santen, R. A.; Kuipers, H. P. C. E. The Mechanism of Ethylene Epoxidation, In: Advances in Catalysis, D.D. Eley, Herman Pines, Paul B. Weisz, Editors, Academic Press 1987, 35 , pp. 265-321.

3) Sachtler, W. M. H.; Backx, C.; van Santen, R. A. On the Mechanism of Ethylene Epoxidation. Catal. Rev. 1981, 23, 127-149.

4) Serafin, J. G.; Liu, A. C.; Seyedmonir, S. R. Surface Science and the Silver-Catalyzed Epoxidation of Ethylene: An Industrial Perspective. J. of Mol. Catal. A: Chem. 1998, 131, 157168. 
5) Bukhtiyarov, V. I.; Knop-Gericke, A. Ethylene Epoxidation over Silver Catalysts, In: Nanostructured Catalysts: Selective Oxidations, C. Hess, R. Schlögl, Editors, Cambridge: Royal Society of Chemistry 2011, pp. 214-247.

6) Stegelmann, C.; Schiødt, N. C.; Campbell, C. T.; Stoltze, P. Microkinetic Modeling of Ethylene Oxidation over Silver. J. Catal. 2004, 221, 630-649.

7) Özbek, M. O.; Onal I.; Van Santen, R. A.; Ethylene epoxidation catalyzed by chlorinepromoted silver oxide. J. Phys.: Condens. Matter 2011, 23, 404202.

8) Özbek, M. O.; Van Santen, R. A.; The Mechanism of Ethylene Epoxidation Catalysis. Catal. Lett. 2013, 143, 131-141.

9) Li, W.-X.; Stampfl, C.; Scheffler, M. Insights into the Function of Silver as an Oxidation Catalyst by ab initio Atomistic Thermodynamics. Phys. Rev. B 2003, 68, 165412.

10) Reichelt, R.; Günther, S.; Rößler, M.; Wintterlin, J.; Kubias, B.; Jakobib, B.; Schlögl, R. High-pressure STM of the Interaction of Oxygen with $\operatorname{Ag}(111)$. Phys. Chem. Chem. Phys. 2007, 9, 3590-3599.

11) Bocquet, M.-L.; Sautet, P.; Cerda, J.; Carlisle, C. I.; Webb, M. J.; King, D. A. Specific Ethene Surface Activation on Silver Oxide Covered $\operatorname{Ag}\{111\}$ from the Interplay of STM Experiment and Theory. J. Am. Chem. Soc. 2003, 125, 3119-3125.

12) Bukhtiyarov, V. I.; Nizovskii, A. I.; Bluhm, H.; Hävecker, M.; Kleimenov, E.; KnopGericke, A.; Schlögl, R. Combined in situ XPS and PTRMS Study of Ethylene Epoxidation over Silver. J. Catal. 2006, 238, 260-269. 
13) Rocha, T. C. R.; Oestereich, A.; Demidov, D. V.; Hävecker, M.; Zafeiratos, S.; Weinberg, G.; Bukhtiyarov, V. I.; Knop-Gericke, A.; Schlögl, R. The Silver-Oxygen System in Catalysis: New Insights by Near Ambient Pressure X-ray Photoelectron Spectroscopy. Phys. Chem. Chem. Phys. 2012, 14, 4554-4564.

14) Rocha, T. C. R.; Hävecker, M.; Knop-Gericke, A.; Schlögl, R. Promoters in Heterogeneous Catalysis: The Role of $\mathrm{Cl}$ on Ethylene Epoxidation over Ag. J. Catal. 2014, 312, 12-16.

15) Jones, T. E.; Rocha, T. C. R.; Knop-Gericke, A.; Stampfl, C.; Schlögl, R.; Piccinin, S. Thermodynamic and Spectroscopic Properties of Oxygen on Silver under an Oxygen Atmosphere. Phys. Chem. Chem. Phys. 2015, 17, 9288-9312.

16) Schmid, M.; Reicho, A.; Stierle, A.; Costina, I.; Klikovits, J.; Kostelnik, P.; Dubay, O.; Kresse, G.; Gustafson, J.; Lundgren, E.; et al. Structure of $\operatorname{Ag}(111)-p(4 \times 4)-O$ : No Silver Oxide. Phys. Rev. Lett. 2006, 96, 146102.

17) Schnadt, J.; Michaelides, A.; Knudsen, J.; Vang, R. T.; Reuter, K.; Lægsgaard, E.; Scheffler, M.; Besenbacher, F. Revisiting the Structure of the $p(4 \times 4)$ Surface Oxide on $\operatorname{Ag}(111)$. Phys. Rev. Lett. 2006, 96, 146101.

18) Reichelt, R.; Günther, S.; Wintterlin, J.; Moritz, W.; Aballe, L.; Mentes, T. O. Low Energy Electron Diffraction and Low Energy Electron Microscopy Microspot $I / V$ Analysis of the $(4 \mathrm{x} 4) \mathrm{O}$ structure on $\operatorname{Ag}(111)$ : Surface Oxide or Reconstruction? J. Chem. Phys. 2007, 127, 134706.

19) Schnadt, J.; Knudsen, J.; Hu, X. L.; Michaelides, A.; Vang, R. T.; Reuter, K.; Li, Z.; Lægsgaard, E.; Scheffler, M.; Besenbacher, F. Experimental and Theoretical Study of Oxygen Adsorption Structures on Ag(111). Phys. Rev. B, 2009, 80, 075424. 
20) Bukhtiyarov, V. I.; Boronin, A. I.; Prosvirin, I. P.; Savchenko, V. I. Stages in the Modification of a Silver Surface for Catalysis of the Partial Oxidation of Ethylene: II. Action of the Reaction Medium. J. Catal. 1994, 150, 268-273.

21) Campbell, C. T.; Paffett, M. T. Model Studies of Ethylene Epoxidation Catalyzed by the $\operatorname{Ag}$ (110) Surface. Surf. Sci. 1984, 139, 396-416.

22) Bocquet, M.-L.; Michaelides, A.; Loffreda, D.; Sautet, P.; Alavi, A.; King, D. A. New Insights into Ethene Epoxidation on Two Oxidized $\mathrm{Ag}\{111\}$ Surfaces. J. Am. Chem. Soc. 2003, $125,5620-5621$.

23) Couves, J.; Atkins, M.; Hague, M.; Sakakini, B. H.; Waugh, K. C. The Activity and Selectivity of Oxygen Atoms Adsorbed on a $\mathrm{Ag} / \alpha-\mathrm{Al}_{2} \mathrm{O}_{3}$ Catalyst in Ethene Epoxidation. Catal. Lett. 2005, 99, 45-53.

24) Carlisle, C. I.; Fujimoto, T.; Sim, W. S.; King, D. A. Atomic Imaging of the Transition between Oxygen Chemisorption and Oxide Film Growth on Ag\{111\}. Surf. Sci., 2000, 470, 1531.

25) Günther, S.; Böcklein, S.; Wintterlin, J.; Niño, M. A.; Menteş, T. O.; Locatelli, A. Locating Catalytically Active Oxygen on $\operatorname{Ag}\left(\begin{array}{lll}1 & 1 & 1\end{array}\right)$-A Spectromicroscopy Study. ChemCatChem 2013, 5, 3342-3350.

26) Günther, S.; Menteş, T. O.; Niño, M. A.; Locatelli, A. Böcklein, S.; Wintterlin, J. Desorption Kinetics from a Surface Derived from Direct Imaging of the Adsorbate Layer. Nature Comm. 2014, 5, 3853 . 
27) Cant, N. W.; Hall, W. K. Catalytic Oxidation: VI. Oxidation of Labeled Olefins over Silver. J. Catal. 1978, 52, 81-94.

28) Linic, S.; Barteau, M. A. Formation of a Stable Surface Oxametallacycle that Produces Ethylene Oxide. J. Am. Chem. Soc. 2002, 124, 310-317.

29) Linic, S.; Barteau, M. A. Control of Ethylene Epoxidation Selectivity by Surface Oxametallacycles. J. Am. Chem. Soc. 2003, 125, 4034-4035.

30) Christopher, P.; Linic, S. Engineering Selectivity in Heterogeneous Catalysis: Ag Nanowires as Selective Ethylene Epoxidation Catalysts. J. Am. Chem. Soc. 2008, 130, 11264-11265.

31) Kokalj, A.; Gava, P.; de Gironcoli, S.; Baroni, S. What Determines the Catalyst's Selectivity in the Ethylene Epoxidation Reaction. J. Catal. 2008, 254, 304-309.

32) Greeley, J.; Mavrikakis, M. On the Role of Subsurface Oxygen and Ethylenedioxy in Ethylene Epoxidation on Silver. J. Phys. Chem. C 2007, 111, 7992-7999.

33) Ozbek M. O.; Onal, I.; van Santen, R. A. Effect of Surface and Oxygen Coverage on Ethylene Epoxidation. Top. Catal. 2012, 55, 710-717.

34) Twigg, G. H. The Mechanism of the Catalytic Oxidation of Ethylene. I. Experiments Using a Flow System. Proc. Roy. Soc. London A: Math., Phys. and Eng. Sci. 1946, 188, 92-104.

35) Kenson, R. E.; Lapkin, M. Kinetics and mechanism of ethylene oxidation. Reactions of ethylene and ethylene oxide on a silver catalyst. J. Phys. Chem. 1970, 74, 1493-1502. 
36) Jones, T. E.; Rocha, T. C. R.; Knop-Gericke, A.; Stampfl, C.; Schlögl, R.; Piccinin, S. Insights into the Electronic Structure of the Oxygen Species Active in Alkene Epoxidation on Silver. ACS Catal. 2015, 5, 5846-5850.

37) Giannozzi, P.; Baroni, S.; Bonini, N.; Calandra, M.; Car, R.; Cavazzoni, C.; Ceresoli, D.; Chiarotti, G. L.; Cococcioni, M.; Dabo, I.; et al. QUANTUM ESPRESSO: A Modular and OpenSource Software Project for Quantum Simulations of Materials. J. Phys.: Condens. Matter 2009, 21,395502 .

38) Perdew, J. P.; Burke, K.; Ernzerhof, M. Generalized Gradient Approximation Made Simple. Phys. Rev. Lett. 1997, 78, 1396-1396.

39) Dal Corso, A. Pseudopotentials periodic table: From H to Pu. Comput. Mater. Sci. 2014, 95, 337-350.

40) Marzari, N.; Vanderbilt, D.; De Vita A.; Payne, M. C. Thermal Contraction and Disordering of the Al(110) Surface. Phys. Rev. Lett. 1999, 82, 3296-3299.

41) Grimme, S. Semiempirical GGA-type Density Functional Constructed with a Long-Range Dispersion Correction. J. Comp. Chem. 2006, 27, 1787-1799.

42) Becke, A. D.; Johnson, E. R. A Unified Density-Functional Treatment of Dynamical, Nondynamical, and Dispersion Correlations. II. Thermochemical and Kinetic Benchmarks. J. Chem. Phys. 2007, 127, 124108.

43) Otero-de-la-Roza, A.; Johnson, E. R. Van der Waals Interactions in Solids using the Exchange-Hole Dipole Moment Model. J. Chem. Phys. 2012, 136, 174109. 
44) Pehlke, E.; Scheffler, M. Evidence for Site-Sensitive Screening of Core Holes at the Si and Ge (001) Surface. Phys. Rev. Lett. 1993, 71, 2338-2341.

45) Kaushik, V. K. XPS Core Level Spectra and Auger Parameters for Some Silver Compounds, J. Electron. Spectrosc. Relat. Phenom. 1991, 56, 273-277.

46) Rößler, M.; Geng, P.; Wintterlin, J. A High-Pressure Scanning Tunneling Microscope for Studying Heterogeneous Catalysis. Rev. Sci. Instrum. 2005, 76, 023705.

47) Bare, S. R.; GriffithsK.; , Lennard, W. N.; Tang, H. T. Generation of Atomic Oxygen on $\operatorname{Ag}(111)$ and $\operatorname{Ag}(110)$ using NO2: a TPD, LEED, HREELS, XPS and NRA Study. Surf. Sci. 1995, 342, 185-198.

48) Campbell, C. T.; Paffett, M. T. The Interactions of O2, CO and CO2 with Ag(110). Surf. Sci. 1984, $143,517-535$.

49) Pascal, M.; Lamont, C.; Baumgärtel, P.; Terborg, R.; Hoeft, J.; Schaff, O.; Polcik, M.; Bradshaw, A.; Toomes, R.; Woodruff, D. Photoelectron Diffraction Study of the Ag(110)-(2×1)O Reconstruction. Surf. Sci. 2000, 464, 83-90.

50) Yang, L.; Rahman, T. S.; Bracco, G.; Tatarek, R. Missing-Row Reconstruction of Ag(110) Induced by a p(2×1) Oxygen Overlayer. Phys. Rev. B 1989, 40, 12271-12279.

51) Zambelli, T.; Barth, J. V.; Wintterlin, J. Formation Mechanism of the O-induced Added-Row Reconstruction on Ag(110): A Low-Temperature STM Study. Phys. Rev. B 1998, 58, 1266312666. 
52) Solomon, J. L.; Madix, R. J.; Stöhr, J. Orientation of Ethylene and Propylene on $\operatorname{Ag}(110)$ from Near Edge X-ray Adsorption Fine Structure. J. Chem. Phys. 1990, 93, 8379-8382.

53) Bocquet, M. L.; Loffreda, D. Ethene Epoxidation Selectivity Inhibited by Twisted Oxametallacycle: A DFT Study on Ag Surface-Oxide. J. Am. Chem. Soc. 2005, 127, 172071725.

54) Barteau, M. A.; Bowker, M.; Madix, R. J. Formation and Decomposition of Acetate Intermediates on the $\operatorname{Ag}(110)$ Surface. J. Catal. 1981, 67, 118-128.

55) Sault, A. G.; Madix, R. J. The Mechanism of Acetate Oxidation on $\operatorname{Ag}(110)$. Surf. Sci. 1986, $172,598-614$.

56) Grönbeck, H.; Klacar, S.; Martin, N. M.; Hellman, A.; Lundgren, E.; Andersen, J. N. Mechanism for Reversed Photoemission Core-Level Shifts of Oxidized Ag. Phys. Rev. B 2012, 85,115445 .

57) Sim, W. S.; Gardner, P.; King, D. A. Surface-Bound Helical Polyacetaldehyde Chains and Bidentate Acetate Intermediates on $\operatorname{Ag}\{111\}$ J. Am. Chem. Soc. 1996, 118, 9953-9959.

58) Sim, W. S.; Gardner, P.; King, D. A. Multiple Bonding Configurations of Adsorbed Formate on $\operatorname{Ag}\{111\}$. J. Phys. Chem. 1996, 100, 12509-12516.

59) Polzonetti, G.; Alnot, P.; Brundle, C. R. The Adsorption and Reactions of NO2 on the $\operatorname{Ag}(111)$ Surface: I. XPS/UPS and Annealing Studies between 90 and 300 K. Surf. Sci. 1990, $238,226-236$. 
60) Yeh, J. J.; Lindau, I. Atomic subshell photoionization cross sections and asymmetry parameters: $1 \leqslant Z \leqslant 103$. At. Data. Nucl. Data Tables 1985, 32, Pages 1-155.

61) Böcklein, S.; Günther, S.; Reichelt, R.; Wyrwich, R.; Joas, M.; Hettstedt, C.; Ehrensperger, M.; Sicklinger, J.; Wintterlin, J. Detection and Quantification of Steady-State Ethylene Oxide Formation over an $\operatorname{Ag}(111)$ Single Crystal. J. Catal. 2013, 299, 129-136.

62) Campbell, C. T. Atomic and molecular oxygen adsorption on Ag(111). Surf. Sci. 1985, 157, 43-60. 